\title{
Propranolol (Inderal) in Persistent Ventricular Fibrillation
}

\author{
GRAEME SLOMAN,* M.B., B.SC., M.R.C.P., M.R.C.P.ED., M.R.A.C.P. ; JAMES S. ROBINSON, $\dagger$ M.B., M.R.A.C.P. ; \\ KENNETH MCLEAN, $\ddagger$ M.D., PH.D., M.R.A.C.P.
}

Brit. med. F., 1965, 1, 895-896

Pronethalol, a beta-adrenergic-blocking agent, has been used successfully in the treatment of supraventricular and ventricular arrhythmias (Stock and Dale, 1963 ; Grandjean and Rivier, 1963 ; Johnstone, 1964 ; Payne and Senfield, 1964). Vaughan Williams and Sekiya (1963) demonstrated that ventricular fibrillation produced in guinea-pigs by the infusion of ouabain could be prevented and controlled by beta-sympathetic blockade. This finding raised the possibility of the use of beta-adrenergicblocking agents in the treatment of the arrhythmias accompanying digitalis intoxication and in the prevention and control of ventricular fibrillation. Pronethalol was associated with the occurrence of thymic tumours in experimental animals, and it has since been replaced by propranolol (Inderal; 1-isopropylamino-3-(1-naphthyloxy)propan-2-ol hydrochloride), which has the same beta-sympathetic-blocking action but a greatly increased therapeutic ratio (Hamer et al., 1964 ; Srivastava et al., 1964 ; Prichard and Gillam, 1964 ; Chamberlain and Howard, 1964).

We here report our experience in treating three patients with recurrent ventricular fibrillation, using propranolol.

\section{Case 1}

A man aged 44 had a proved anteroseptal myocardial infarction complicated by left ventricular failure at the age of 40 . Four and a half years later he developed angina of effort, which persisted for eight months and culminated in an acute anterior myocardial infarction.

On examination his blood-pressure was $120 / 80 \mathrm{~mm}$. $\mathrm{Hg}$ and he had both a third and a fourth heart sound. Sedation, analgesics, and anticoagulant therapy were begun. Pain persisted for 48 hours, during which time his electrocardiogram was monitored; occasional ventricular extrasystoles were the only abnormality. Moderate left ventricular failure ensued and the patient was digitalized. The S.G.O.T. rose to a peak of 112 units.

Twenty-one days after his admission to hospital he argued heatedly with the ward sister, insisting that he should be allowed to walk instead of being restricted to a wheelchair. After walking about 25 yards down the corridor he collapsed and was found to be pulseless. Immediate cardiac massage was instituted and a directcurrent defibrillator was obtained. Initial attempts to defibrillate, using an external shock of 400 watt-seconds, were unsurccessful until the metabolic acidosis was corrected by the administration of a total of $35 \mathrm{~g}$. of THAM (tris(hydroxymethyl)aminomethane). The arterial $\mathrm{pH}$ initially was $\mathbf{7 . 1 8}$ and after finally establishing sinus rhythm 7.35 .

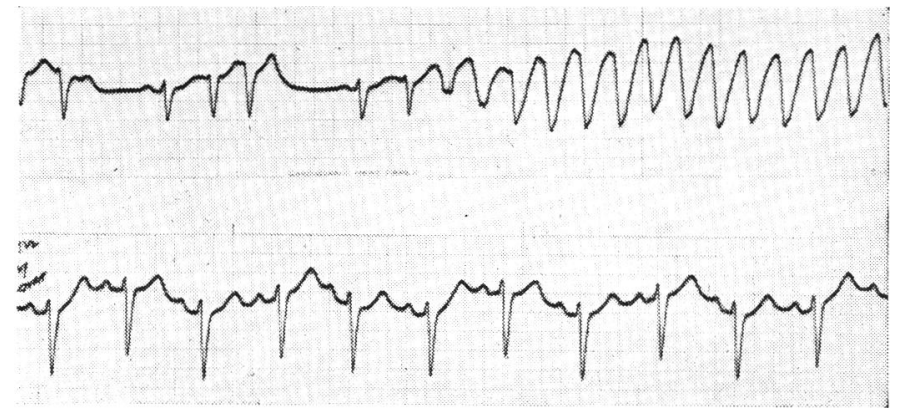

FIG. 1.-Case 1. Upper tracing shows the onset of ventricular fibrillation. The lower tracing illustrates regular rhythm which was established
after $22 \mathrm{mg}$. of propranolol.
During that afternoon ventricular tachycardia turning into ventricular fibrillation repeatedly recurred (Fig. 1). The patient was heavily sedated, and over the next two hours $2 \mathrm{~g}$. of procainamide was given intravenously without effect. Direct-current defibrillation was required on 62 occasions over the next 30 hours and in addition a total $3.7 \mathrm{~g}$. of procainamide was administered without significant effect on the number of attacks.

Propranolol in a dose of $22 \mathrm{mg}$. was given intravenously over 10 minutes. After $12 \mathrm{mg}$. ventricular extrasystoles were less frequent; following an additional $10 \mathrm{mg}$. no further arrhythmias were observed. Circulatory failure with severe hypotension persisted and the patient died 40 minutes later.

\section{Case 2}

A woman aged 44 had been treated for chronic bronchitis, obesity, and heart failure. On the day prior to her admission she had attended the out-patient department complaining of profuse diarrhoea and vomiting. Further vomiting and weakness resultec in her admission. On examination she was found to be collapsed. deeply cyanosed, and the peripheral pulses were absent. External cardiac massage and emergency ventilation were immediately begun The electrocardiogram showed ventricular fibrillation.

Defibrillation, using a direct-current counter-shock, was attempted on eight occasions. Although sinus mechanism returned for a fer beats it rapidly reverted to ventricular fibrillation. Propranolol was given intravenously in a dose of $20 \mathrm{mg}$. Cardiac massage was continued and after a further direct-current counter-shock of $40 \mathrm{C}$ watt-seconds the arrhythmia returned to a sinus mechanism. Peripheral circulation improved with a systolic blood-pressure of 100 $\mathrm{mm}$. Hg. Because of obesity and prolonged external cardiac massage a tracheostomy was performed. During this procedure she became anoxic and cardiac arrest occurred with asystole. After external cardiac massage and correction of the anoxia the rhythm was noticed to be complete heart-block with a ventricular rate of 50. The systolic blood-pressure varied from 90 to $110 \mathrm{~mm}$. $\mathrm{Hg}_{8}$ over the next 12 hours. Ventilation was maintained with an intermittent positive-pressure respirator (Bird Mark 8). No ectopic ventricular beats, ventricular flutter, or fibrillation were noted during continuous monitoring. Death occurred in asystole while the tracheostomy was being aspirated 12 hours after the last bout of ventricular fibrillation.

At necropsy the heart weighed $513 \mathrm{~g}$. There was right ventricular hypertrophy but no other macroscopic or microscopical abnormality. Death was probably due to digitalis toxicity and dehydration.

\section{Case 3}

A 61-year-old man presented to hospital with upper abdominal pain and with a past history of gall-bladder disease. On examination the blood-pressure was $175 \mathrm{~mm}$. $\mathrm{Hg}$ and the pulse rate 86 per minute. There was diffuse epigastric tenderness. While awaiting an $x$-ray examination of the abdomen the patient collapsed and when seen was clinically dead. External cardiac massage and emergency ventilation were begun immediately. The electrocardiogram showed ventricular fibrillation. An intravenous infusion was started and $250 \mathrm{mEq}$ of sodium bicarbonate $(8.7 \%)$ given.

External direct-current defibrillation was attempted, and after the third shock, using 400 watt-seconds, atrial fibrillation with a systolic

* Assistant Cardiologist, Royal Melbourne Hospital, Melbourne, Victoria, Australia.

† Research Assistant, Royal Melbourne Hospital, Melbourne, Victoria, Australia. Working under Research Grant G.162, National Hear: Foundation of Australia.

¥ Director, Cardiovascular Diagnostic Service, Alfred Hospital, Melbourne. Victoria, Australia. 
blood pressure of $180 \mathrm{~mm}$. $\mathrm{Hg}$ was obtained. Digoxin was administered intravenously in a dose of $1 \mathrm{mg}$., followed by $200 \mathrm{mg}$. of procainamide. The patient did not regain full consciousness, and was agitated and irritable; $10 \mathrm{mg}$. of papaveretum was given.

After transferring him to the special-care ward the blood-pressure was $170 / 100 \mathrm{~mm}$. Hg, with regular sinus rhythm at a rate of 90 per minute. The jugular venous pressure was not elevated. Although there was some paradoxical movement of the chest, breath sounds were well heard and there were no adventitiae. Half an hour after his admission ventricular fibrillation recurred and was treated with immediate external cardiac massage and defibrillation. The patient was given $750 \mathrm{mg}$. of procainamide intravenously and a further 100 $\mathrm{mEq}$ of sodium bicarbonate. However, 30 minutes later ventricular flutter occurred and this was reverted with direct-current countershock at 200 watt-seconds. A further dose of $250 \mathrm{mg}$. of procainamide was administered. The electrocardiogram showed numerous bizarre ventricular ectopics with runs of ventricular tachycardia. Four more attacks of ventricular flutter progressing to ventricular fibrillation recurred despite further doses of procainamide and intravenous sodium Amytal (Fig. 2).

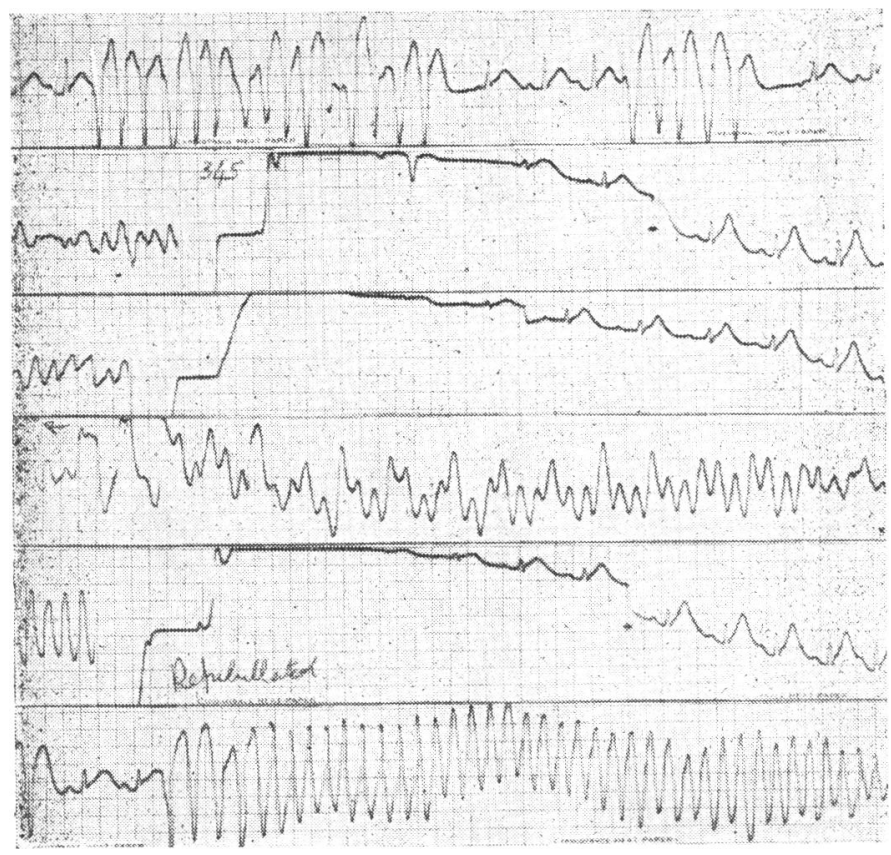

FIG. 2.-Case 3. Selected portions of the electrocardiogram illustrating the repeated attacks of ventricular flutter-fibrillation prior to the use of propranolol.

After the seventh episode $15 \mathrm{mg}$. of propranolol was infused slowly. After this no ventricular ectopics were noted and no further attacks of ventricular flutter or ventricular fibrillation occurred and the blood-pressure remained stable. Elective tracheostomy was performed and the patient was continued on sedation and oral propranolol $10 \mathrm{mg}$. three times a day. He was fully conscious the day after his arrest and made good progress. There were no further cardiac complications. Peak S.G.O.T. was 168 units and the electrocardiogram showed evidence of a recent anterior myocardial infarction. When reviewed six weeks after the cardiac arrest the patient's general condition was good. There was no evidence of any cardiac decompensation and there was no chest pain.

\section{Discussion}

In three patients propranolol was effective in suppressing recurrent ventricular fibrillation after other drug therapy had failed.

Vaughan Williams (1963) suggested that adrenergic-blocking agents may be of value in the control of digitalis-induced ventricular fibrillation. Our second patient was thought to have ventricular fibrillation as a result of digitalis intoxication. Propranolol was effective in preventing recurrent episodes of fibrillation. However, once control was achieved, complete atrioventricular block occurred. The cause of this disorder of conduction was unknown but propranolol or digitalis must be regarded with suspicion. It is possible that propranolol may lead to complete atrioventricular block.

Two patients had recurrent ventricular fibrillation following acute myocardial infarction. In one (Case 3) propranolol was life-saving, in that it controlled the ventricular rhythm after seven episodes of ventricular flutter-fibrillation. In this patient the subsequent clinical course and S.G.O.T. suggested that infarction had not been large. In the other patient (Case 1) two episodes of myocardial infarction had been documented, and with each evidence of left ventricular failure had appeared. In this patient multiple episodes of ventricular tachycardiafibrillation were controlled by intravenous propranolol. However, control of the arrhythmia was followed by persistent hypotension. This may have been the result of an extensive degree of underlying myocardial damage or a direct effect of propranolol. Beta-adrenergic-blocking agents have been shown to decrease myocardial contractility (Harrison et al., 1963). It is presumed that in the presence of extensive myocardial infarction any decrease of contractility in remaining viable muscle may result in hypotension. Thus it is suggested that when used in patients with severe infarction the dose of propranolol should be kept to a minimum.

With intravenous administration propranolol was found to have a rapid and effective anti-arrhythmic action; this is a prerequisite in treating patients in such a desperate situation. When administered by the intravenous route, propranolol should be injected slowly, under electrocardiographic control, and once the ventricular arrhythmia has been controlled injection should be discontinued. The maximum single dose should not exceed $10 \mathrm{mg}$.

Propranolol is an effective agent in controlling ventricular arrhythmias. Ventricular fibrillation is a common mode of death in patients with myocardial infarction (Robinson et al., 1965). Propranolol may be of value as prophylaxis against ventricular fibrillation in such patients. A controlled trial of this drug in acute myocardial infarction would be of value.

\section{Summary}

We report three cases of recurrent episodes of ventricular fibrillation controlled by propranolol (Inderal) given intravenously. In one patient with acute myocardial infarction this treatment was life-saving.

Dangers of propranolol may include hypotension, particularly in patients with extensive underlying myocardial damage. In such patients care should be exercised in administering propranolol; a maximum intravenous dose of $10 \mathrm{mg}$. is recommended.

Propranolol was of value in controlling digitalis-induced ventricular fibrillation.

Propranolol may be of value as a prophylactic agent in patients with mild myocardial infarction.

We wish to thank Dr. Margaret Henderson and Dr. H. B. Kay for permission to treat patients under their care. Mr. V. G. Stott, Pharmaceutical Section, I.C.I., Melbourne, made available the propranolol used in this study.

\section{REPERENCES}

Chamberlain, D. A., and Howard, J. (1964). Brit. Heart f., 26, 213. Grandjean, T., and Rivier, J. L. (1963). Schweiz. med. Wchr., 93, 1101. Brit. med. \%., 2, 720 .

Harrison, D. C., Ross, J., iun., Glick, G., Chidsey, C. A., and Braunwald, E. (1963). Clin. Res. Proc., 11, 167.

Johnstone, M. (1964). Brit. F. Anaesth., 36, 224.

Payne, J. P., and Senfield, R. M. (1964). Brit. med. Y., 1, 603.

Prichard, B. N. C.. and Gillam, P. M. S. (1964). Ibid., 2, 725

Robinson, J. S., Sloman, G., Mathew, T. H., and Goble, A. J. (1965). Amer, Heart 7. In press.

Srivastava, S. C., Dewar, H. A., and Newell, D. J. (1964). Brit. med. Y., 2, 724.

2, 724. P., and Dale, N. (1963). Ibid., 2, 1230.

Stock, J. P. P., and Dale, N. (1963). Ibid., 2, 1230.
Vaughan Williams, E. M. (1963). Amer. Heart Y., 66, 569.

Vaughan Williams, E. (1963). Lancet, 1, 420. 